\title{
Ovariectomy at 3 or 10 weeks of age does not affect the ventilatory response to hypoxia in adult rats
}

\author{
Aida Bairam \\ Department of Pediatrics, Laval University, Centre de Recherche du Centre Hospitalier Universitaire de Québec (CRCHUQ) , Hôpi- \\ tal Saint-François d'Assise (HSFA), Québec, Canada \\ Email: aida.bairam@crsfa.ulaval.ca
}

Received 29 April 2012; revised 4 June 2012; accepted 20 July 2012

\begin{abstract}
Although an ovariectomy is the routine approach used to study the role of ovarian hormones on respiratory control, the results have often been contradictory. We tested the hypothesis that the ventilatory response to hypoxia is modified by the age at which the ovariectomy is performed. Female rats were ovariectomized either atan early (3 weeks old, i.e., prepubertal) or late (10 weeks old, i.e., adult) stage, and ventilation was then assessed at 12 weeks of age using wholebody plethysmography. The control group included sham-operated rats that had undergone the same surgical procedure but were not ovariectomized. Independent of the age at which surgery was performed, ovariectomy significantly decreased circulating progesterone and 17-b-estradiol levels without reducing them below their detection threshold. Despite that decrease, there was no difference in baseline minute ventilation or in the ventilatory response to hypoxia $\left(\mathrm{FiO}_{2}=12 \%, 20 \mathrm{~min}\right.$; expressed as the percentage of increase from baseline) between ovariectomized and sham-operated rats. These results suggest that ovariectomy at either a young or at an adult age is insufficient to completely suppress circulating hormones and disrupt the regulation of ventilation.
\end{abstract}

Keywords: Hypoxia; Ovarian Hormones; Ventilation

\section{INTRODUCTION}

In adult mammals, including humans, an important body of evidence shows that the ovarian hormones progesterone and estradiol are potent respiratory stimulants $[1,2]$. Both hormones act on peripheral (via carotid body chemoreceptors) and central respiratory control systems (via the medullary nucleus) to increase breathing in response to either hypoxia or hypercapnia [2,3]. Indeed, these hormones are considered to have a protective role against disrupted breathing during sleep in females before the menopausal period [1,2,4]. Ovariectomy is a standard approach used to study the effect of ovarian hormones on the hypoxic ventilatory response. However, the results obtained with this approach have often been contradictory [1,5]. That contradiction may partly depend on the delay between the surgery modulating the level of circulating ovarian hormones and the assessments of ventilation. In this regard, we tested the hypothesis that performing ovariectomy at an early age and not at an adult age disrupts the hypoxic response in rats. Ventilation at rest and in response to hypoxia was measured in adult female rats (12 weeks old) that were ovariectomized either at 3 (young rats, prepubertal) or 10 weeks old (adult). Concomitantly, the plasma levels of ovarian hormones were assessed to evaluate the potential relationship between hormone levels and ventilation.

\section{MATERIALS AND METHODS}

\subsection{Animals and Ventilatory Recording}

Experiments were performed on 12-week-old female Sprague-Dawley rats $(n=41)$ born and raised in our animal care facilities. The animals originated from 6 different litters to reduce litter-specific effects. Rats were supplied with food and water ad libitum and maintained under standard animal care conditions $\left(21^{\circ} \mathrm{C}, 12 \mathrm{~h}: 12 \mathrm{~h}\right.$ dark:light cycle, lights on at 8:00 A.M. and off at 8:00 P.M.). Mating, litter manipulation, surveillance and ventilatory recording using whole body, flow-through plethysmography were all performed according to our standard procedures, which have been previously described in detail [6,7]. Ventilatory parameters were first recorded under baseline ventilation $\left(\mathrm{FiO}_{2}=21 \%\right)$ for $10 \mathrm{~min}$, and rats were then exposed to moderate hypoxia $\left(\mathrm{FiO}_{2}=12 \%\right)$ for $20 \mathrm{~min}$. On the day of the experiment, each rat was acclimated to the plethysmographic chamber (model PLY 3223, Buxco Electronics, Sharon, CT) for approximately 30 min before the baseline recording. Body temperature was measured rectally at the end of the baseline recording 
and hypoxic exposure using a thermocouple for rodents (Harvard, Holliston, MA, USA). Baseline measurements were made when the animal was quiet but awake and ventilatory activity was stable. Breathing frequency (fr/ $\mathrm{min}$ ) and tidal volume (Vt ml BTPS/100 g) were measured using data acquisition software (IOX, EMKA Technologies, Falls Church, VA, USA) and were used to calculateminute ventilation $\left(\mathrm{V}_{\mathrm{E}}=\mathrm{fr} \times \mathrm{V}_{\mathrm{T}} \mathrm{ml} / \mathrm{min} / 100 \mathrm{~g}\right)$. Barometric pressure, chamber temperature, and humidity were measured to correct $\mathrm{V}_{\mathrm{T}}$ as previously described [6, 7]. The flow of gas into the plethysmography chamber was maintained constant at $2.0 \mathrm{~L} / \mathrm{min}$. The oxygen concentration flowing in and out of the chamber was continuously measured (Oxygen analyzer model S-3A, Ametek, Pittsburgh, PA, USA) and used for subsequent calculations of oxygen consumption $\left(\mathrm{VO}_{2}=\mathrm{ml} / \mathrm{min} / 100 \mathrm{~g}\right)$ $[6,7]$. Oxygen consumption was assessed at baseline and at the end of the hypoxic exposure. All experiments were performed between 9:00 and 12:00 A.M.

All protocols were in accordance with the Canadian Council on Animal Care Guidelines and were approved by the Laval University Animal Protection Committee.

\subsection{Surgery}

Rats underwent sham surgery (intact) or ovariectomy (OVX) under isoflurane anesthesia $(2 \%-2.5 \%$ in air) at 3 (young rats, prepubertal) or 10 weeks (adult) of age. Briefly, a small midline abdominal incision was made, the adipose tissue containing the ovaries was gently pulled, the ducts and blood vessels connected to the ovaries were sutured and then cut, and the ovaries were removed. Shamoperated rats underwent an identical intervention but without blood vessel ligation or ablation of the ovaries. Each rat received standard post-surgical care, which included buprenorphine ( $5 \mathrm{mg} / \mathrm{kg}$, subcutaneously), $5 \mathrm{ml}$ of Ringer's lactate (subcutaneously; only for adult rats) and an antibiotic (Baytril: $5 \mathrm{mg} / \mathrm{kg} / \mathrm{d}$, for a total of $3 \mathrm{~d}$ ). In all rats, the hypoxic response was then evaluated at 12 weeks of age, independent of surgery time.

\subsection{Plasma Hormones}

To exclude any possible effects of hypoxia on steroid levels, progesterone and estradiol were assessed in rats (5 - 6 in each group) issued from 3 other litters not used for the hypoxic response experiments described above. Rats were deeply anesthetized with isoflurane ( $\sim 5 \%)$, and blood was taken by cardiac puncture.The samples were centrifuged immediately and stored at $-20^{\circ} \mathrm{C}$ until analysis. Progesterone and estradiol levels were assessed using standard chemiluminescence kits (Roche Diagnostics, Laval, QC, Canada) as previously described [7]. All ventilatory measurements and plasma hormone samplings were performed between 9:00 and 12:00 A.M.

\subsection{Data Analyses and Statistic}

Respiratory frequency, tidal volume, and minute ventilation were first calculated on a minute-by-minute basis using data analysis software (Data analyst, EMKA Technologies). The baseline value represents the mean of 5 consecutive min of steady respiration before exposure to hypoxia. The temporal dynamics of the ventilatory variables in response to hypoxia were averaged every $2 \mathrm{~min}$ over the first $10 \mathrm{~min}$ of exposure (early phase), while the last 10 min were averaged in 5-min epochs (late phase) and expressed as the percent (\%) change from baseline. An ANOVA for one or multiple factors, including the age at the time of surgery (young vs. adult), type of surgery (sham vs. OVX), and condition (hypoxia), was used (Stat View 4.5). A p $<0.05$ was considered statistically significant. Data are expressed as the mean \pm SEM.

\section{RESULTS}

\subsection{Ovariectomy Does Not Affect the Baseline Variables}

Table 1 shows the baseline variables measured in sham (intact) or ovariectomized (OVX) rats. Body weight and body temperature were comparable in all groups independent of their age when surgery was performed (i.e., 3 or 10 weeks old) (Table 1). The baseline ventilatory variables and oxygen consumption were also similar between all groups of rats (Table 1).

\subsection{Ovariectomy Decreased Plasma Hormone Levels}

Ovariectomy significantly reduced the progesterone and estradiol levels whether it was performed at 3 or 10 weeks of age (Table 2). Interestingly, the progesterone and estradiol levels were lower and higher, respectively, in rats ovariectomized at 10 weeks than at 3 weeks of age, suggesting that the hormone levels were dependent on the age when surgery was performed.

Table 1. Body weight, body temperature and baseline ventilatory parameters in adult female intact (sham-operated) or ovariectomized (OVX) rats.

\begin{tabular}{ccccc}
\hline & \multicolumn{2}{c}{ OVX at 3 weeks } & \multicolumn{2}{c}{ OVX at 10 weeks } \\
\cline { 2 - 5 } $\mathrm{n}$ & sham & OVX & sham & OVX \\
\cline { 2 - 5 } & 11 & 10 & 8 & 12 \\
$\mathrm{BW}(\mathrm{g})$ & $273 \pm 6$ & $305 \pm 11$ & $300 \pm 17$ & $307 \pm 14$ \\
$\mathrm{~Tb}\left({ }^{\circ} \mathrm{C}\right)$ & $37.9 \pm 0.2$ & $37.8 \pm 0.2$ & $38.2 \pm 0.3$ & $37.9 \pm 0.3$ \\
$\mathrm{fr}(/ \mathrm{min})$ & $73 \pm 2$ & $80 \pm 2$ & $71 \pm 4$ & $74 \pm 4$ \\
$\mathrm{~V}_{\mathrm{T}}(\mathrm{ml} / 100 \mathrm{~g})$ & $0.72 \pm 0.03$ & $0.67 \pm 0.04$ & $0.74 \pm 0.04$ & $0.72 \pm 0.04$ \\
$\mathrm{~V}_{\mathrm{E}}(\mathrm{ml} / \mathrm{min} / 100 \mathrm{~g})$ & $51 \pm 4$ & $53 \pm 3$ & $52 \pm 4$ & $51 \pm 3$ \\
$\mathrm{VO}_{2}(\mathrm{ml} / \mathrm{min} / 100 \mathrm{~g})$ & $3.2 \pm 0.2$ & $3.3 \pm 0.2$ & $3.0 \pm 0.3$ & $3.0 \pm 0.1$ \\
\hline
\end{tabular}

BW: Body weight; $\mathrm{Tb}$ : Body temperature; fr: Breathing frequency; $\mathrm{V}_{\mathrm{T}}$ : Tidal volume; $\mathrm{V}_{\mathrm{E}}$ : Minute ventilation; $\mathrm{VO}_{2}$ : Oxygen consumption. 
Table 2. Steroid hormone levels in adult female intact (sham) or ovariectomized (OVX) rats.

\begin{tabular}{|c|c|c|c|c|}
\hline & \multicolumn{2}{|c|}{ OVX at 3 weeks } & \multicolumn{2}{|c|}{ OVX at 10 weeks } \\
\hline & sham & OVX & sham & OVX \\
\hline $\begin{array}{l}\text { Progesterone } \\
\text { (nmol/l) }\end{array}$ & $\begin{array}{c}72 \pm 12 \\
(35-108)\end{array}$ & $\begin{array}{c}21 \pm 3^{*} \\
(14-36)\end{array}$ & $\begin{array}{c}35 \pm 8 \\
(10-65)\end{array}$ & $\begin{array}{l}7 \pm 2^{*+} \\
(3-14)\end{array}$ \\
\hline $\begin{array}{c}17 \beta \text {-estradiol } \\
(\mathrm{pmol} / \mathrm{l})\end{array}$ & $\begin{array}{c}284 \pm 25 \\
(224-366)\end{array}$ & $\begin{array}{c}82 \pm 12^{*} \\
(24-105)\end{array}$ & $\begin{array}{c}291 \pm 40 \\
(178-444)\end{array}$ & $\begin{array}{c}142 \pm 13^{*+} \\
(103-170)\end{array}$ \\
\hline
\end{tabular}

${ }^{*} \mathrm{p}<0.01$ vs. sham; ${ }^{\dagger} \mathrm{p}<0.01$ vs. OVX at 3 weeks old. Data are the mean \pm SEM. Each group contained 5 - 6 rats that were not subjected to the hypoxic test.

\subsection{Ovariectomy Does Not Affect the Hypoxic Response}

The dynamic changes in ventilatory variables in response to hypoxia (\% changes from baseline) are shown in Figure 1. Exposure to hypoxia significantly increased minute ventilation compared to baseline in either the shamorovariectomized rats. This response was not influenced by the agewhen surgery was performed (Figure 1(a), hypoxia effect: $\mathrm{p}<0.001$; hypoxia $\mathrm{x}$ age at surgery $\mathrm{x}$ type of surgery: $p=N S$ ). This increase in minute ventilation was due to an increase in breathing frequency (Figure 1(b)) but not in tidal volume (Figure 1(c)). There was no statistical interaction between surgery and hypoxia $(p=N S)$ for either respiratory frequency or tidal volume (Figures 1(b) and (c)). Oxygen consumption was similar between sham and ovariectomized rats (Figure 2), independent of their age at the time of surgery.

\section{DISCUSSION}

The findings observed in this study clearly show that the hypoxic ventilatory response remains unaffected in adult female rats (12 weeks old), independent of the age at which the ovariectomy was performed ( 3 or 10 weeks), despite a significant decrease in plasma estradiol and progesterone levels. These results suggest that the ovarian hormones remaining after an ovariectomy are sufficient for the hypoxic chemoreflex.

\subsection{Ovariectomy and Hormone Levels}

The significant decrease observed in estradiol and progesterone levels confirmed that the surgery was adequate and efficient. However, it is possible that the capacity of extra-ovarian organs to synthesize progesterone and estradiol prevented the ovariectomy from reducing both hormones to below their detection thresholds, despite these surgeries having been performed at an early age. In addition to the gonads, progesterone is synthesized from cholesterol in the adrenal glands [1,8-10]. Unfortunately, specific antagonists to progesterone receptors are lacking, and the widely used drug mifepristone (RU486) has antiglucocorticoid activity. Using such tools in the presence or ab- sence of an adrenalectomy may be more useful [10] for identifying the role of ovarian hormones on ventilation than the ovariectomy alone.

\subsection{Ovarian Hormones and Ventilation}

It is clear that progesterone and estradiol are well-known actors in respiratory control in adult [1,2] and developing rats [11], although their proposed role has been controversial [5]. In fact, hyperventilation during pregnancy and the efficiency of hormone replacement therapy for reducing the apnea/hypopnea index in postmenopausal women with sleep-disrupted breathing have been taken as evidence of a stimulatory role of ovarian hormones on breathing $[1,2]$. Both phases of the hypoxic response, the early increase (mainly related to peripheral carotid body chemoreceptor activation) and the late steady state (mainly related to central integration), were not affected by ovariectomy and were independent of the age at which the surgery was performed. The absence of a difference between sham-operated and ovariectomized rats does not support the notion that ovarian hormones modulate respiratory activity. The present work corroborates a study by Mortola [5] in which female rats were ovariectomized at 2 to 3 weeks of age, and measurements were performed at approximately 2 months of age. However, it is noteworthy that, in Mortola's study, ovarian steroids were not assessed and his conclusion was based only on the differences in the magnitude of hypoxic chemoreflexes between sham-operated and ovariectomized female rats. Our study shows that an ovariectomy reduces but does not completely eliminate these hormones from circulation. It is therefore possible that ovariectomy had no effect on the parameters measured, either in Mortola's study [5] or in the present study, due to the persistence of circulating hormones, which may explain, at least in part, the conflicting results reported in the literature $[1,2,5]$. Interestingly, our study, which measures both plasma hormones and the hypoxic response, suggests: 1) That a concentration of progesterone as low as $7 \mathrm{nmol} / \mathrm{L}$ is sufficient to influence ventilation and 2) That this progesterone-related increase in hypoxic chemosensitivity is also potentiated by estradiol $[1,2]$. Thus, although the circulating levels of progesterone and estradiol were reduced $\sim 2$ - 3-fold by ovariectomy, such concentrations may likely be sufficient to ensure an adequate response to hypoxia. Finally, the central nervous system synthesizes "central neurosteroids", including progesterone, independently of circulating hormones [12], which interact at the brain stem or on the motor neuron level [1]. The central neurosteroids might play an important role in the hypoxic response, at least during the late phase, which is primarily related to central (brain stem) activation of respiratory control. In this regard, it may be relevant to mention that hypoglossal nerve activity differs 
Surgery at 3 weeks old

(a)

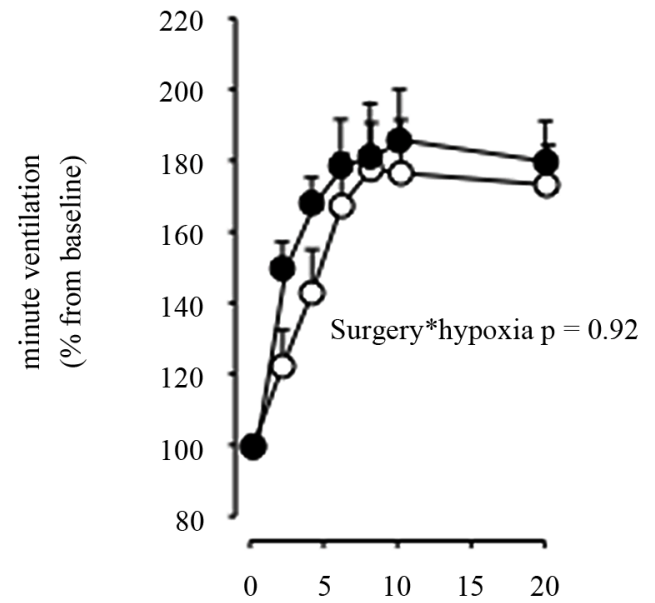

(b)

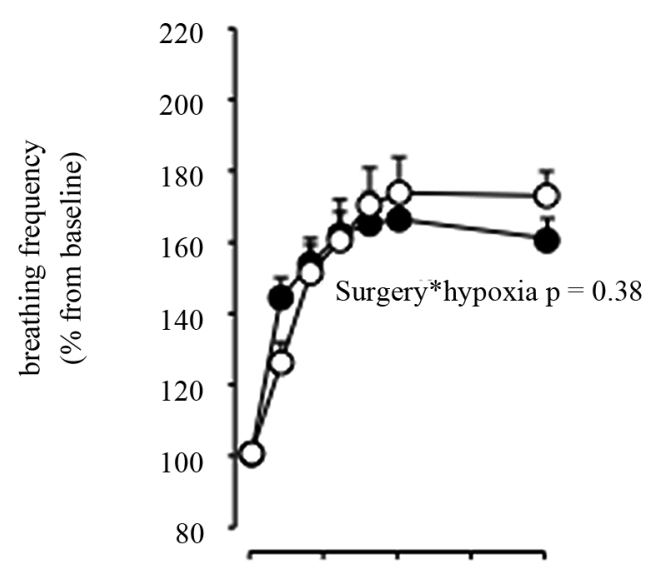

(c)

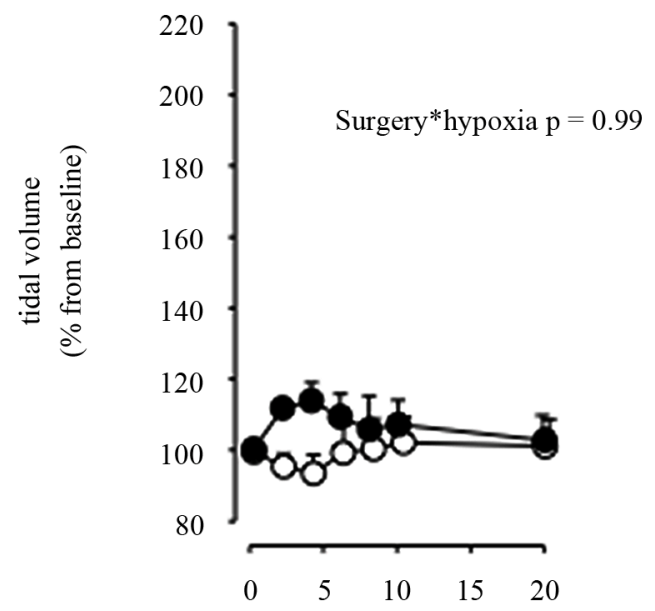

Hypoxia $(12 \%, \min )$
Surgery at 10 weeks old

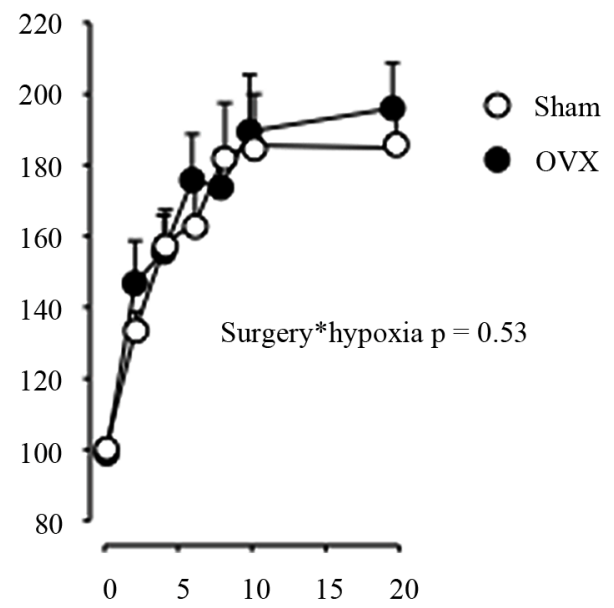



Figure 1. Time course of respiratory variables in response to hypoxia $\left(\mathrm{FiO}_{2}=12 \% \mathrm{O}_{2}\right)$ in intact (sham) or ovariectomized (OVX) adult female rats at early (3 weeks) and late (10 weeks) ages. Each time point of minute ventilation is significantly different from baseline in all groups studied; labels were not added to the figures for clarity purposes. Data represent the mean \pm SEM. 


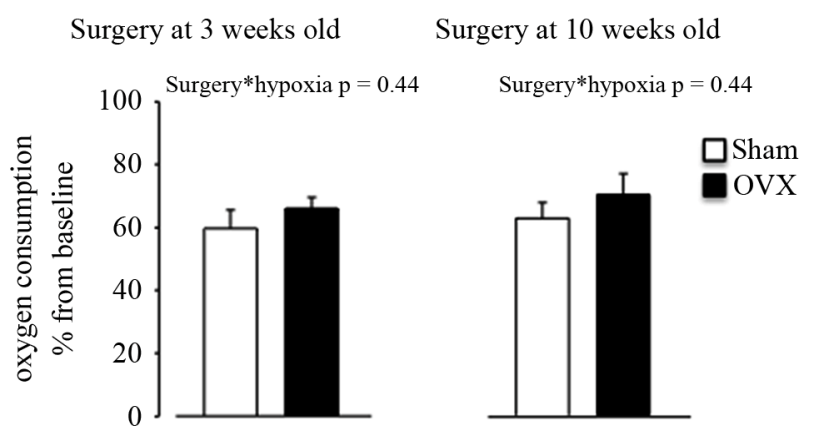

Figure 2. Oxygen consumption at the end of hypoxic exposure in intact (sham) or ovariectomized (OVX) adult female rats at early (3 weeks) and late (10 weeks) ages. Data represent the mean \pm SEM.

in the estrus and diestrus cycles [13] and that the progesterone and estrogen receptors are expressed in brain stem respiratory nuclei $[14,15]$. Additionally, local infiltration of progesterone into the nucleus tractus solitarius enhances phrenic nerve activity [16].

In conclusion, ovariectomy at either a young or an adult age is insufficient to completely suppress circulating hormones and disrupt the regulation of ventilation. A transgenic model lacking the progesterone receptor gene may be a promising alternative for assessing the involvement of ovarian hormones in the control of breathing.

\section{ACKNOWLEDGEMENTS}

This study was supported by an operating grant MOP-119272 to A. B. from the CIHR. We thank Ms. Mélanie Pelletier and Sylvie Viger for their help with animal care. We also thank Ms. Cécile Julien for her meticulous technical assistance. We acknowledge the expert assistance of Dr. Richard Poulin in the revision of the manuscript.

\section{REFERENCES}

[1] Behan, M. and Wenninger, J.M. (2008) Sex steroidal hormones and respiratory control. Respiratory Physiology \& Neurobiology, 164, 213-221.

doi:10.1016/j.resp.2008.06.006

[2] Behan, M. and Kinkead, R. (2011) Neuronal control of breathing: Sex and stress hormones. Comprehensive Physiology, 1, 2101-2139.

[3] Jensen, D., Wolfe, L.A., Slatkovska, L., et al. (2005) Effects of human pregnancy on the ventilatory chemoreflex response to carbon dioxide. American Journal of Physiology Regulatory, Integrative and Comparative Physiology, 288, R1369-R1375. doi:10.1152/ajpregu.00862.2004

[4] Lin, C.M., Davidson, T.M., Ancoli-Israel, S. (2008) Gender differences in obstructive sleep apnea and treatment implications. Sleep Medicine Reviews, 12, 481-496. doi:10.1016/j.smrv.2007.11.003
[5] Mortola, J.P. and Saiki, C. (1996) Ventilatory response to hypoxia in rats: Gender differences. Respiration Physiology, 106, 21-34. doi:10.1016/0034-5687(96)00064-3

[6] Julien, C.A., Niane, L., Kinkead, R., et al. (2010) Carotid sinus nerve stimulation, but not intermittent hypoxia, induces respiratory LTF in adult rats exposed to neonatal intermittent hypoxia. American Journal of Physiology Regulatory, Integrative and Comparative Physiology, 299, R192-R205. doi:10.1152/ajpregu.00707.2009

[7] Bairam, A., Montandon, G., Joseph, V., et al. (2009) Enhancement of the breathing frequency response to hypoxia by neonatal caffeine treatment in adult male rats: The role of testosterone. Respiratory Physiology \& Neurobiology, 165, 261-265. doi:10.1016/j.resp.2008.11.002

[8] Behan, M., Zabka, A.G., Thomas, C.F., et al. (2003) Sex steroid hormones and the neural control of breathing. Respiratory Physiology \& Neurobiology, 136, 249-263. doi:10.1016/S1569-9048(03)00086-7

[9] Stanton, B., Giebisch, G., Klein-Robbenhaar, G., et al. (1985) Effects of adrenalectomy and chronic adrenal corticosteroid replacement on potassium transport in rat kidney. The Journal of Clinical Investigation, 75, 1317-1326. doi:10.1172/JCI111832

[10] Walf, A.A. and Frye, C.A. (2005) Antianxiety and antidepressive behavior produced by physiological estradiol regimen may be modulated by hypothalamic-pituitaryadrenal axis activity. Neuropsychopharmacology, 30, 12881301.

[11] Soliz, J. and Joseph, V. (2005) Perinatal steroid exposure and respiratory control during early postnatal life. Respiratory Physiology \& Neurobiology, 149, 111-122. doi:10.1016/j.resp.2005.01.013

[12] Baulieu, E.E., Robel, P. and Schumacher, M. (2001) Neurosteroids: Beginning of the story. International Review of Neurobiology, 46, 1-32. doi:10.1016/S0074-7742(01)46057-0

[13] Zabka, A.G., Behan, M. and Mitchell, G.S. (2001) Selected contribution: Time-dependent hypoxic respiratory responses in female rats are influenced by age and by the estrus cycle. Journal of Applied Physiology, 91, 28312838.

[14] Behan, M. and Thomas, C.F. (2005) Sex hormone receptors are expressed in identified respiratory motoneurons in male and female rats. Neuroscience, 130, 725-734. doi:10.1016/j.neuroscience.2004.09.058

[15] Haywood, S.A., Simonian, S.X., van der Beek, E.M., et al. (1999) Fluctuating estrogen and progesterone receptor expression in brainstem norepinephrine neurons through the rat estrous cycle. Endocrinology, 140, 3255-3263. doi:10.1210/en.140.7.3255

[16] Bayliss, D.A., Millhorn, D.E., Gallman, E.A., et al. (1987) Progesterone stimulates respiration through a central nervous system steroid receptor-mediated mechanism in cat. Proceedings of the National Academy of Sciences of the United States of America, 84, 7788-7792. doi:10.1073/pnas.84.21.7788 